\title{
Effect of Hydrothermal Treatment on Milling Characteristics of Finger Millet
}

\author{
M. Rajasekhar ${ }^{1 *}$, L. Edukondalu ${ }^{2}$, D.D. Smith $^{3}$ and G. Veeraprasad ${ }^{2}$ \\ ${ }^{1}$ Indian Agricultural Research Institute, New Delhi, India \\ ${ }^{2}$ College of Agricultural Engineering, Bapatla, India \\ ${ }^{3}$ College of Food Science and Technology, Pulivendula, India \\ *Corresponding author
}

\section{A B S T R A C T}

Keywords

Hydrotheraml treatment, Milling yield, Broken percentage and seed coat matter

Article Info

Accepted:

15 September 2018

Available Online:

10 October 2018
The present study was undertaken to determine the effect of hydrothermal treatment on milling characteristics of finger millet (PPR 2700, Vakula). Finger millet grains were soaked in two different water temperatures of $30{ }^{\circ} \mathrm{C}$ and $70{ }^{\circ} \mathrm{C}$ with 24 and 1 hour 45 minutes soaking times respectively. Treatments were followed by steaming at $1,1.5$ and 2 $\mathrm{kg} \mathrm{cm}-1$ pressures. The samples were dried at $40{ }^{\circ} \mathrm{C}$ and equilibrated to two different final moisture contents of 12 and 14\% (wet basis). Hydrothermally treated samples were milled using rice polisher and the product was classified into head rice, broken and seed coat matter. From the milling studies, it was observed that the increase in soaking temperature and steaming pressure increased milling yield. Hydrothermal treatment of finger millet increased the hardness of the grain and this resulted in improved milling yield upon milling. The treatment with soaking temperature of $70{ }^{\circ} \mathrm{C}$, steaming pressure of $2 \mathrm{~kg} \mathrm{~cm}^{-2}$ dried to a final moisture content of $14 \%$ was found to be the best with milling yield, broken percentage and seed coat percentage of $87.80 \%, 4.44 \%$ and $7.68 \%$ respectively.

\section{Introduction}

Finger millet is the important minor millet which contains high amounts of calcium and other minerals as compared to other cereals. The main constituents of the millet kernel are seed coat (testa), embryo and endosperm (Chandra et al., 2006). Finger millet usage is restricted due to their culinary properties and the form of availability limiting to prepare fewer products only. The main reason for this limited use is its seed coat being associated with grain (Dharmaraj et al., 2013). Though there is some useful ingredient present with the seed coat like dietary fibre, the much portion of seed coat also contains the antinutritional factors like tannin, saponins and polyphenol.

These factors in turn fetch the whole mass off flavoured and bad odour and appearance, which is usually being unacceptable by the new generation people. In addition to this currently the finger millet is being available in the whole flour form including the powdered seed coat matter within it. Finger millet is normally consumed in the form of flour-based foods such as roti (unleavened pancake), 
mudde (stiff porridge/dumpling) and ambli (thin porridge) (Malleshi et al., 2007).

In the present study more emphasis was given to change the form of finger millet in order to make it available for preparation of novel food product such as milled finger millet grain (hereafter it denotes the grain without seed coat or testa). Generally the grain finger millet contains an intact seed coat or testa with its endosperm matter. Whenever efforts were kept to remove this seed coat the grain gets pulverised including with seed coat and results in formation of whole flour, which was mainly due to the fragile nature of the finger millet. Hence it becomes necessary to change the fragile nature of the finger millet grain to harder one in order to make any mechanical processing operations over the grain. The experiment focuses on imparting harder texture to the grain through subjecting them to hydrothermal treatment and to convert the total grain matter into compact homogeneous gelatinized mass. The hydrothermally treated grains possess harder texture are less susceptible to breakage during milling operation consequently the seed coat matter only get abraded from the surface. Hence, the main objective of this study was to determine the effect of soaking temperature and steaming pressure on milling characteristics of finger millet.

\section{Materials and Methods}

Finger millet of PPR-2700 (Vakula) variety was used for milling. Finger millet grains with membranous pericarp were dehulled in ragi pearler at Post Harvest Technology Centre, Bapatla and these samples were used for further study.

\section{Hydrothermal treatment of finger millet}

Finger millet grains were soaked in two different temperatures of $30{ }^{\circ} \mathrm{C}$ and $70{ }^{\circ} \mathrm{C}$ with 24 and 1 hour 45 minutes soaking times respectively (Ushakumari, 2009). A water bath (M.B. Instruments, Delhi) was used for soaking finger millet at $70{ }^{\circ} \mathrm{C}$ and good quality plastic containers were used to soak the grains at $30{ }^{\circ} \mathrm{C}$. Grains after soaking were immediately subjected to steaming at steaming pressures of $1,1.5$ and $2 \mathrm{~kg} / \mathrm{cm}^{2}$ in order to get the grains completely gelatinized. The grains were spread as thin layer in bottom of the cylindrical container which was placed in the autoclave $(250 \times 450 \mathrm{~mm}$, Optics Technology, Delhi). After steaming, finger millet grains were dried in a tray dryer [C.M. Equipment \& Instruments (India) Pvt. Ltd., Bangalore]. The preliminary experiments on drying conditions of the material were aimed at preparation of the milled finger millet. The examination of the dried finger millet for the physical features such as formation of fissures, deformation in shape, variations in size, shape and color, clearly indicated that drying the finger millet at $40{ }^{\circ} \mathrm{C}$ was most appropriate with respect to the various quality attributes suitable for milling. Accordingly, the steamed finger millet was dehydrated at $40{ }^{\circ} \mathrm{C}$. The finger millet grains were dried to average final moisture contents of $12.15 \%$ and $14.09 \%$ (w.b.). The grain moisture content was measured with the electronic moister meter (AG-QMT, LCGC Bio Analytic Solutions LLP) and the samples were removed from the dryer after reaching required moister content.

Various combinations of soaking, steaming and drying (treatments along with the control) are shown in Tables 1 and 2.

\section{Milling of hydrothermally treated finger millet}

The milled finger millet is totally a new and novel product from the finger millet and the information on its preparation as well as its functional properties is scanty. Hence, in the present study the finger millet was 
hydrothermally treated and then milled using rice polisher (6704, INDOSAW, Osaw Industrial Products Pvt. Ltd., Haryana). The flow chart of preparation of milled finger millet from hydrothermally treated finger millet grains was shown in figure 1 . Hydrothermally treated finger millet was fed to the rice polisher for milling. The speed of carborundum disc used for finger millet milling was maintained at $2950 \mathrm{rpm}$. Based on preliminary trials, it was found that a sample of $100 \mathrm{~g}$ resulted in optimum milling in the polisher. Residence time of the sample inside the polisher for milling was maintained as 20 seconds and a sample is milled in two passes rather than single pass for better milling yield.

\section{Classification of milled Sample}

The milled sample consists of head grain (milled), brokens and seed coat fraction. To classify these fractions sieve analysis was performed using standard sieves of $1003 \mu \mathrm{m}$, $600 \mu \mathrm{m}$ sizes. The over size of $1003 \mu \mathrm{m}$ was head grain, under size of $1003 \mu \mathrm{m}$ and over size of $600 \mu \mathrm{m}$ was termed as brokens and under size of $600 \mu \mathrm{m}$ was termed as seed coat matter (Ushakumari, 2009). The terminology related to the classified milled sample is discussed below.

\section{Milling yield}

Milling yield in percent is defined as the ratio of the mass of the head grain to that of the total sample (Dharmaraj et al., 2013) and is expressed as:

$$
\text { Milling yield }(\%)=\frac{\text { Weight of head grain }}{\text { Weight of total sample }} \times 100
$$

\section{Broken percentage}

It is defined in percentage as the ratio of broken grains to the total sample (Ushakumari, 2009) and is expressed as
Broken percentage $(\%)=\frac{\text { Weight of brokens }}{\text { Weight of total sample }} \times 100$

\section{Seed coat percentage}

It is defined in percentage as the ratio of seed coat matter to the total sample (Ushakumari, 2009) and is expressed as

Seed coat percentage $(\%)=\frac{\text { Weight of seed coat }}{\text { Weight of total sample }} \times 100$

\section{Degree of milling}

The degree of milling is the percentage of the grain removed mainly in the form of seedcoat during milling. The degree of milling is calculated as ratio of seed coat matter plus broken to the total sample fed to the polisher.

\section{Output capacity}

Output capacity in $\mathrm{kgh}^{-1}$ is calculated as mass of milled finger millet achieved per unit time.

\section{Statistical analysis}

Factorial Completely Randomised Design (FCRD) was used and the effect of different independent variables on the dependent were analysed. Statistical Package for the Social Sciences (SPSS) software was used to analyse the data.

\section{Results and Discussion}

Effect of hydrothermal treatment on milling characteristics of finger millet

\section{Effect of soaking and steaming conditions on milling yield}

As the steaming pressure was increased, milling yield also increased. In case of finger millet soaked at $30{ }^{\circ} \mathrm{C}$ and steamed at $2 \mathrm{~kg}$ $\mathrm{cm}^{-2}$, highest milling yields recorded was $78 \%$ 
and $86.23 \%$ at $12.15 \%$ and $14.09 \%$ moisture contents, respectively. Similarly, finger millet soaked at $70{ }^{\circ} \mathrm{C}$ and steamed at $2 \mathrm{~kg} \mathrm{~cm}^{-2}$, recorded highest milling yields of $81.16 \%$ and $87.88 \%$ at $12.15 \%$ and $14.09 \%$ moisture contents, respectively.

Milling yield varied significantly (at $\mathrm{P}<0.01$ ) with grain soaking temperature, grain steam pressure and moisture content of grain at the time of milling. From the results shown in figure 2 , an increase in soaking temperature and steaming pressure increased milling yield. Hydrothermal treatment of finger millet increased the hardness of the grain and this resulted in improved milling yield upon milling. Besides, moisture content of the grain also influenced the milling yield. Finger millet milled at $12.15 \%$ moisture content resulted in less milling yield compared to grains milled at $14.09 \%$. It was observed that the higher moisture content $(14.09 \%)$ facilitated the leathery nature to the seed coat and hence seed coat was easily abraded from the grain.

\section{Effect of soaking and steaming conditions on broken percentage}

Broken percentage of milled finger millet (MFM) decreased from $25.43 \%$ to $12.71 \%$ and from $15.42 \%$ to $6.63 \%$ at $12.15 \%$ and $14.09 \%$ moisture contents respectively with increase in steam pressure, in case of grains soaked at 30 ${ }^{\circ} \mathrm{C}$. The broken percentage of milled finger millet (MFM) decreased from $20.66 \%$ to $9.42 \%$ and from $9.52 \%$ to $4.44 \%$ at $12.15 \%$ and $14.09 \%$ moisture contents respectively with increase in steam pressure, in case of grains soaked at $70{ }^{\circ} \mathrm{C}$.

As the steaming pressure was increased, broken percentage decreased. In case of finger millet soaked at $30{ }^{\circ} \mathrm{C}$ and steamed at $2 \mathrm{~kg} \mathrm{~cm}^{-}$ ${ }^{2}$, lowest brokens recorded were $12.71 \%$ and $6.63 \%$ at $12.15 \%$ and $14.09 \%$ moisture contents respectively. Similarly, finger millet soaked at $70{ }^{\circ} \mathrm{C}$ and steamed at $2 \mathrm{~kg} \mathrm{~cm}^{-2}$, recorded lowest broken percentage of $9.42 \%$ and $4.44 \%$ respectively at $12.15 \%$ and $14.09 \%$ moisture contents. The property of raw finger millet called brittleness or floury endosperm disappeared after hydrothermal treatment and the breakage was arrested to the great extent.

The broken percentage decreased as the soaking temperature, steaming pressure and moisture content was increased. Soaking temperature, steaming pressure and moisture content significantly influenced broken percentage at $\mathrm{P}<0.01$. From the figure 3 it was clear that the increase in steam pressure improved the hardness of the grain and the broken percentage was inversely proportional to the hardness of the grain. The higher moisture content of the grain reduced the broken percentage as it rendered the seed coat leathery on the grain surface during milling, which enabled easy milling of seed coat without breakage of grain.

\section{Effect of soaking and steaming conditions on seed coat percentage}

The complete milling of grain was achieved only when the total seed coat matter was separated to its full extent, hence it could be inferred that the higher amount of seed coat generated was an indication of higher milling and vice-versa.

But it was also clear that sometimes small amount of endosperm matter also milled and associated with the seed coat matter.

Seed coat separation increased with increase in soaking temperature, steaming pressure and moisture content. The seed coat percentage increased from $4.22 \%$ to $9.29 \%$ and from $5.22 \%$ to $7.14 \%$ at $12.15 \%$ and $14.09 \%$ moisture contents, respectively with increase in steam pressure, in case of grains soaked at $30{ }^{\circ} \mathrm{C}$. 
Table.1 Hydrothermal treatments of finger millet grains soaked in water at $\left(30{ }^{\circ} \mathrm{C}\right)$ for $24 \mathrm{~h}$

\begin{tabular}{|c|c|c|c|c|c|}
\hline \multirow[t]{2}{*}{ Treatments } & \multicolumn{2}{|c|}{ Soaking } & \multicolumn{2}{|c|}{ Steaming } & \multirow{2}{*}{$\begin{array}{l}\text { Final moisture conten } \\
\text { of dried finger millet } \\
(\% \mathrm{w.b.})^{*}\end{array}$} \\
\hline & $\begin{array}{c}\text { Temperature } \\
{ }^{\circ} \mathrm{C}\end{array}$ & $\begin{array}{c}\text { Time } \\
\mathrm{h}\end{array}$ & $\begin{array}{l}\text { Pressure } \\
\mathrm{kg} \mathrm{cm}^{-2}\end{array}$ & $\begin{array}{l}\text { Time } \\
\min \end{array}$ & \\
\hline T1 & \multirow[t]{6}{*}{30} & \multirow[t]{6}{*}{24} & \multirow[t]{2}{*}{1} & \multirow[t]{2}{*}{20} & $12.19 \pm 0.36$ \\
\hline T2 & & & & & $14.18 \pm 0.27$ \\
\hline T3 & & & \multirow[t]{2}{*}{1.5} & \multirow[t]{2}{*}{18} & $12.11 \pm 0.26$ \\
\hline T4 & & & & & $14.14 \pm 0.25$ \\
\hline T5 & & & \multirow[t]{2}{*}{2} & \multirow[t]{2}{*}{16} & $12.10 \pm 0.22$ \\
\hline T6 & & & & & $13.89 \pm 0.39$ \\
\hline
\end{tabular}

Table.2 Hydrothermal treatments of finger millet grains soaked in water at $\left(70{ }^{\circ} \mathrm{C}\right)$ for $1.45 \mathrm{~h}$

\begin{tabular}{|c|c|c|c|c|c|}
\hline \multirow[t]{2}{*}{ Treatments } & \multicolumn{2}{|c|}{ Soaking } & \multicolumn{2}{|c|}{ Steaming } & \multirow{2}{*}{$\begin{array}{l}\text { Final moisture content } \\
\text { of dried finger millet } \\
(\% \text { w.b. }) *\end{array}$} \\
\hline & $\begin{array}{c}\text { Temperature, } \\
{ }^{\circ} \mathrm{C}\end{array}$ & $\underset{\mathrm{h}}{\mathrm{T}}$ Time, & $\begin{array}{l}\text { Pressure, } \\
\mathrm{kg} \mathrm{cm}^{-2}\end{array}$ & $\begin{array}{c}\text { Time, } \\
\text { min }\end{array}$ & \\
\hline T7 & \multirow[t]{6}{*}{$\mathbf{7 0}$} & \multirow[t]{6}{*}{1.45} & \multirow[t]{2}{*}{1} & \multirow[t]{2}{*}{20} & $12.21 \pm 0.19$ \\
\hline T8 & & & & & $14.08 \pm 0.17$ \\
\hline T9 & & & \multirow[t]{2}{*}{1.5} & \multirow[t]{2}{*}{18} & $12.07 \pm 0.16$ \\
\hline T10 & & & & & $14.09 \pm 0.20$ \\
\hline T11 & & & \multirow[t]{2}{*}{2} & \multirow[t]{2}{*}{16} & $12.07 \pm 0.17$ \\
\hline T12 & & & & & $14.05 \pm 0.22$ \\
\hline $\mathbf{T}_{\mathrm{C}}$ & \multicolumn{4}{|c|}{ Raw finger millet (RFM) / Control sample } & $11.50 \pm 0.06$ \\
\hline
\end{tabular}

$*$ The mean value \pm Standard deviation

Fig.1 Flow chart for preparation of hydrothermally treated and milled finger millet

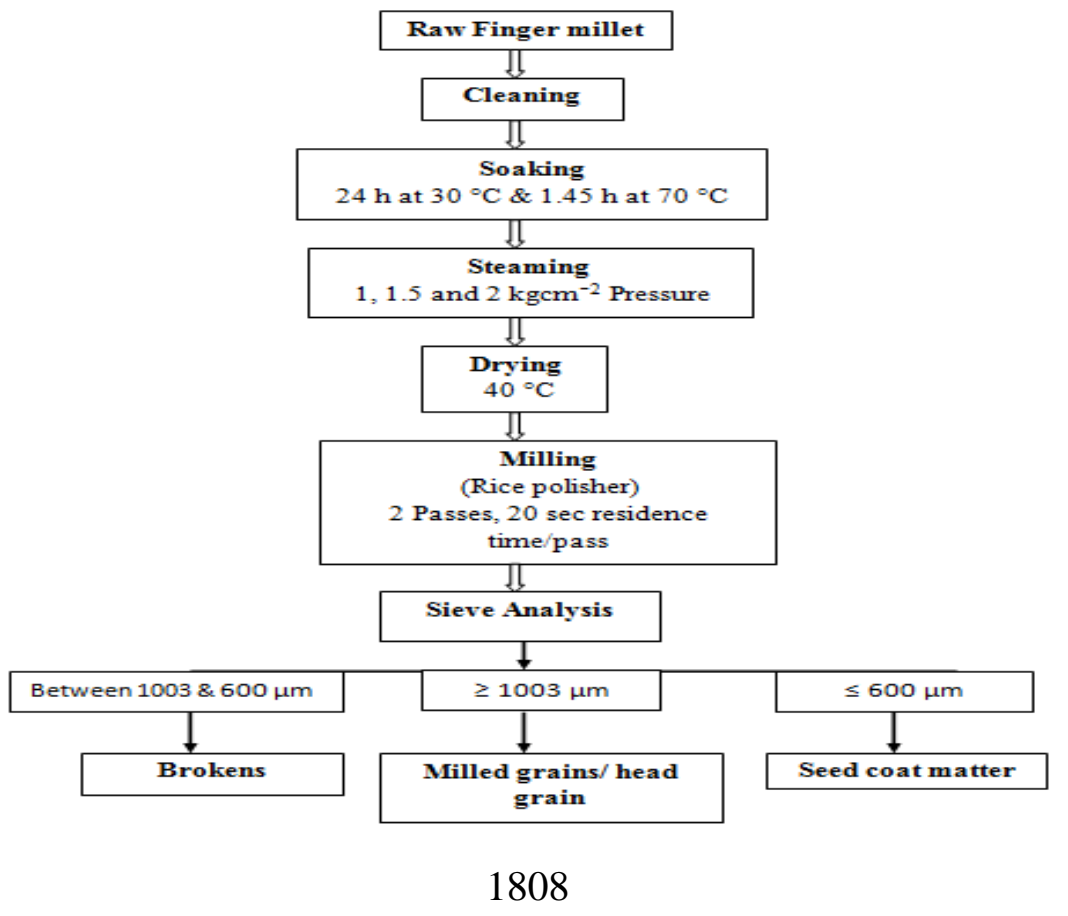


Fig.2 Effect of soaking and steaming conditions on milling yield

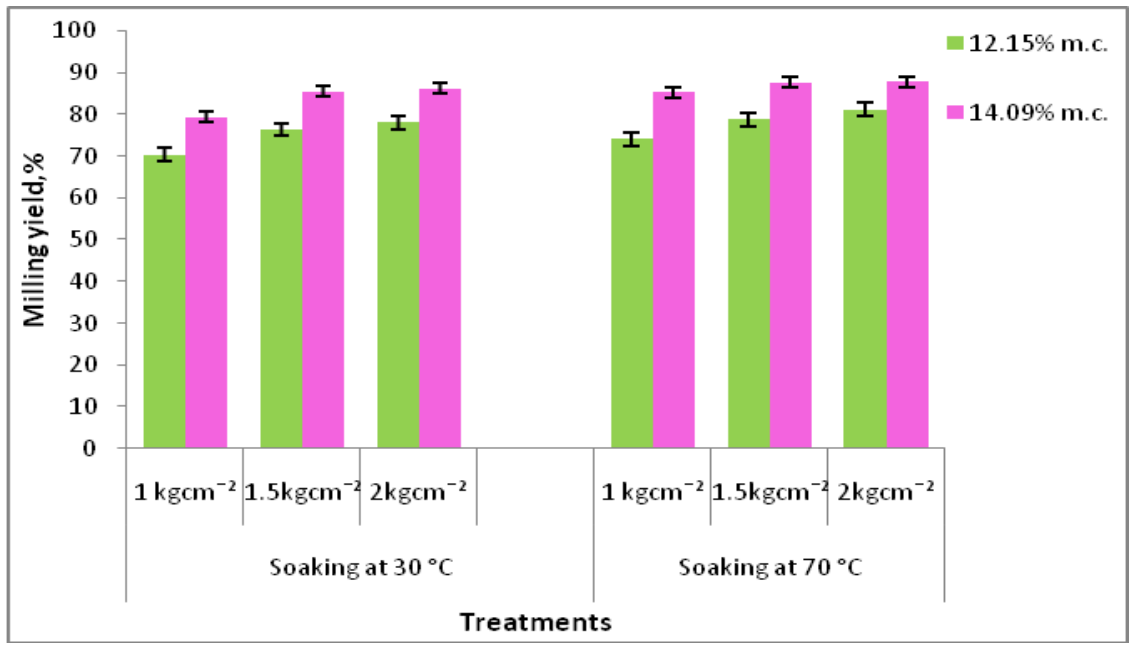

Fig.3 Effect of soaking and steaming conditions on broken percentage

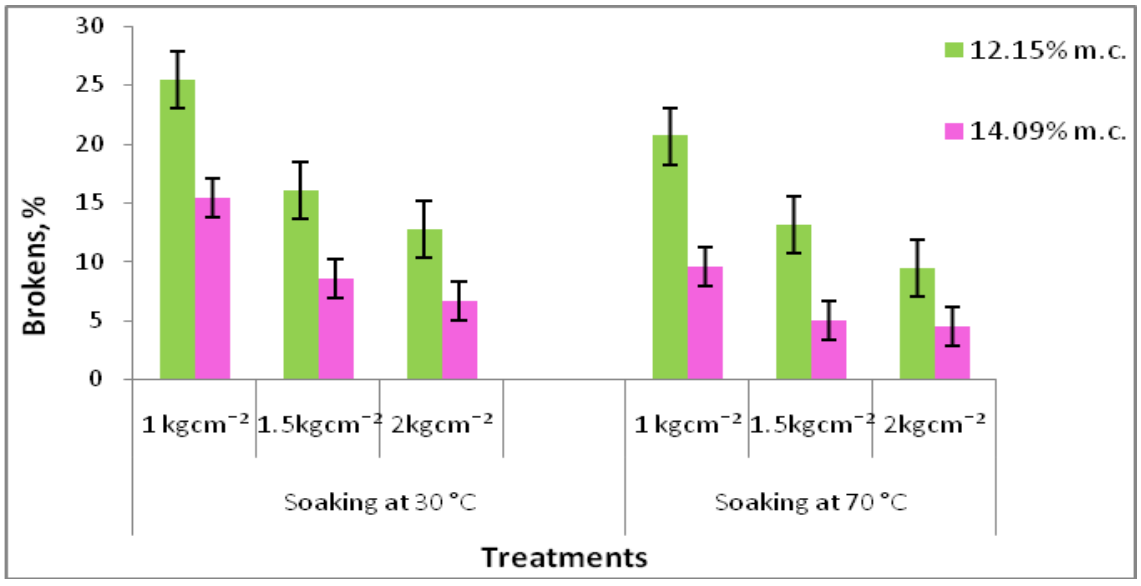

Fig.4 Effect of soaking and steaming conditions on seed coat percentage

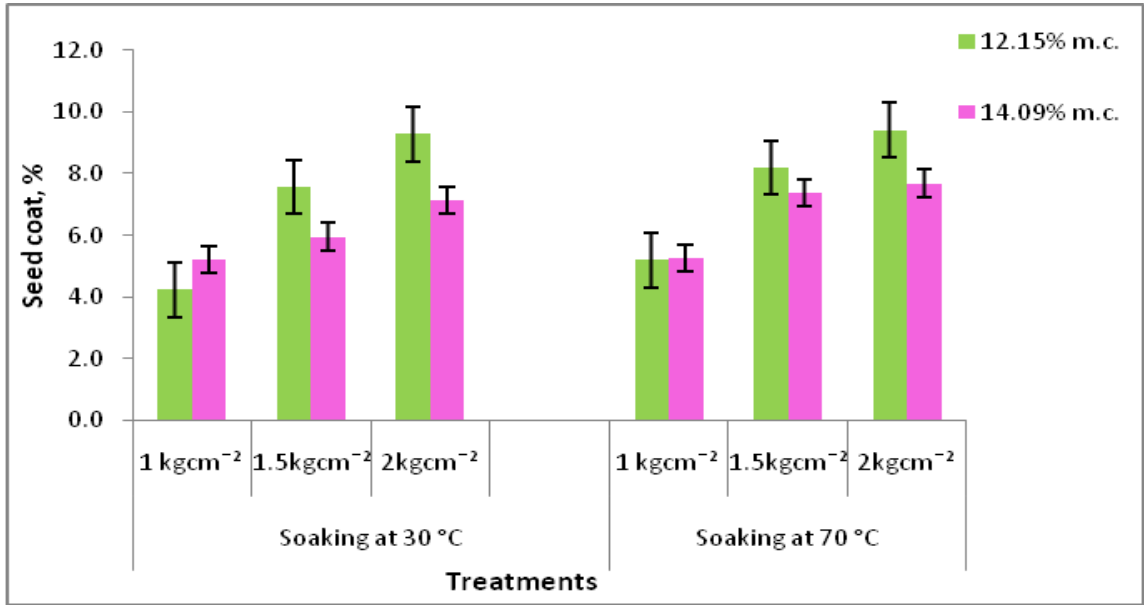


Fig.5 Effect of hydrothermal treatment on degree of milling

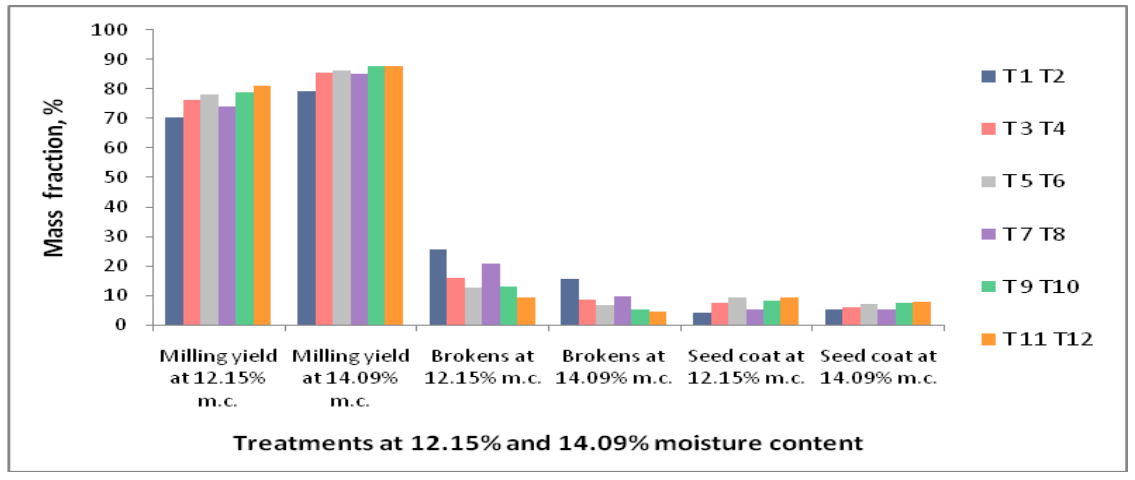

Fig.6 Effect of hydrothermal treatment on output capacity of the polisher

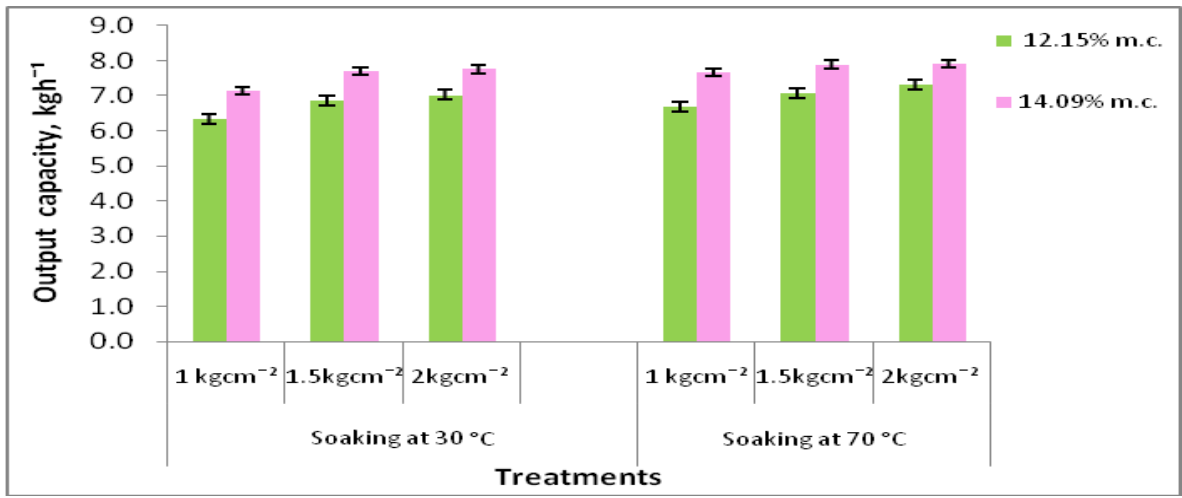

The seed coat percentage increased from $5.20 \%$ to $9.42 \%$ and from $5.26 \%$ to $7.68 \%$ at $12.15 \%$ and $14.09 \%$ moisture contents, respectively with increase in steam pressure, in case of grains soaked at $70{ }^{\circ} \mathrm{C}$ (Fig. 4). The reason for the increased seed coat could be due to an increased hardness upon increased steam pressures, which enabled more milling and hence the seed coat was produced in the same amount. Seed coat percentage varied significantly with the changes in soaking temperature, steaming pressure and moisture content at $\mathrm{P}<0.01$.

\section{Degree of milling}

The degree of milling is the percentage of the grain removed mainly in the form of seedcoat during milling (Shobana and Malleshi, 2007). The optimum conditions for high degree of milling were determined with treatment corresponding to high milling yield, lower broken percentage and higher seed coat matter together.

Treatment No. 12 with soaking temperature of $70{ }^{\circ} \mathrm{C}$, steaming pressure of $2 \mathrm{~kg} \mathrm{~cm}^{-2}$ dried to a final moisture content of $14.09 \%$ was the best among all (Fig. 5).

\section{Effect of pre-treatment conditions on the output capacity of the polisher during milling}

To calculate the output capacity of the polisher, $100 \mathrm{~g}$ of HTM was taken and the polisher was run for 20 seconds. Milling was done in two passes rather than single pass for better milling yield. Output capacity increased with increase in soaking temperature, steaming pressure and moisture content. 
The output capacity increased from 6.33 to 7.02 $\mathrm{kgh}^{-1}$ and from 7.14 to $7.76 \mathrm{kgh}^{-1}$ at $12.15 \%$ and $14.09 \%$ moisture contents respectively, with increase in steam pressure, in case of grains soaked at $30{ }^{\circ} \mathrm{C}$. Output capacity increased from 6.67 to $7.30 \mathrm{kgh}^{-1}$ and from 7.67 to $7.91 \mathrm{kgh}^{-1}$ at $12.15 \%$ and $14.09 \%$ moisture contents respectively with increase in steam pressure, in case of grains soaked at $70{ }^{\circ} \mathrm{C}$ (Fig. 6).

Milling characteristics of the hydrothermally treated millet were influenced by the grain hardness. The increase in soaking temperature and steaming pressure increased milling yield. Hydrothermal treatment of finger millet increased the hardness of the grain and this resulted in improved milling yield upon milling. Finger millet milled at $12.15 \%$ moisture content resulted in less milling yield compared to grains milled at $14.09 \%$.

It was observed that the higher moisture content $(14.09 \%)$ facilitated the leathery nature to the seed coat and hence seed coat was easily abraded from the grain and also the same conditions or feature attained facilitated the less breakage of grain. Seed coat separation increased with increase in soaking temperature, steaming pressure and moisture content.

\section{Acknowledgement}

The authors thank the Acharya N.G. Ranga Agricultural University, College of Agricultural Engineering, Department of Processing and Food Engineering, Bapatla, Andhrapradesh, India to provide the facility to carry out the experimental work and for the financial support during research work.

\section{References}

Chandra, D., Chandra, S. and Sharma, A.K., 2016. Review of Finger millet (Eleusine coracana (L.) Gaertn): a power house of health benefiting nutrients. Food Science and Human Wellness, 5(3), pp.149-155.

Dharmaraj, U., Ravi, R and Malleshi, N.G. 2013. Optimization of process parameters for decortication of finger millet through response surface methodology. Food and Bioprocess Technology. 6(1): 207-216.

Malleshi, N.G. 2007. Nutritional and technological features of ragi (finger millet) and processing for value addition. In Food uses of small millets and avenues for further processing and value addition (pp. 9-19). Bangalore: Project Coordination Cell, All India Coordinated Small Millets Improvement Project, ICAR, UAS, GKVK.

Shobana, S and Malleshi, N.G. 2007. Preparation and functional properties of decorticated finger millet (Eleusine coracana). Journal of Food Engineering. 79(2): 529-538.

Ushakumari, S.R. 2009. Technological and physicochemical characteristics of hydrothermally treated finger millet. $P h . D$ Thesis. University of Mysore, Mysore, India.

Ushakumari, S.R., Rastogi, N.K and Malleshi, N.G. 2007. Optimization of process variables for the preparation of expanded finger millet using response surface methodology. Journal of Food Engineering. 82(1): 35-42.

\section{How to cite this article:}

Rajasekhar, M., L. Edukondalu, D.D. Smith and Veeraprasad, G. 2018. Effect of Hydrothermal Treatment on Milling Characteristics of Finger Millet. Int.J.Curr.Microbiol.App.Sci. 7(10): 18041811. doi: https://doi.org/10.20546/ijcmas.2018.710.206 